\title{
An Overview of Geo-electric Dimensionality of Paraná Basin
}

\author{
Ved P Maurya, Leonardo G. Miquelutti, Sergio . L. Fontes, Emanuele F. La Terra, Observatório Nacional
}

Copyright 2016, SBGf - Sociedade Brasileira de Geofísica

Este texto foi preparado para a apresentação no VII Simpósio Brasileiro de Geofísica Ouro Preto, 25 a 27 de outubro de 2016. Seu conteúdo foi revisado pelo Comitê Técnico do VII SimBGf, mas não necessariamente representa a opinião da SBGf ou de seus associados. E proibida a reprodução total ou parcial deste material para propósitos comerciais sem prévia autorização da SBGf.

\begin{abstract}
A proper knowledge of the structural dimensionality of subsurface, as given by some MT attributes, is an essential tool to guide the generation and tailoring of inversion models presenting meaningful distribution of the resistivity at depth. Presently, we have several approaches available such as Swift and Bahr skews, Groom \& Bailey decompositions, WALDIM dimensionality analysis, Phase Tensor Analysis - PTA, etc., to assess it in complete sense. In the present study, we compared the results from various approaches to extract the clear picture of dimensionality behavior of Paraná basin. The dimensionality results from Bahr, WALDIM and PTA are most consistent and suggest a predominant one dimensional structure for frequencies smaller than $0.1 \mathrm{~Hz}$, and three dimensional behavior for frequencies higher than $0.1 \mathrm{~Hz}$. However, Groom Bailey and Swift approaches are incapable of determining the dimensionality in better way possibly indicating strong 3-D features beneath Paraná basin at deeper depths.
\end{abstract}

Keywords: Dimensionality, Paraná Basin, Magnetotelluric, Phase tensor, Impedance tensor

\section{Introduction}

Dimensionality analysis/distortion correction area is at present mostly performed by Bahr criteria (Bahr, 1991), Groom and Bailey decomposition (Groom and Bailey, 1989), Extended Groom-Bailey decomposition (McNeice and Jones, 2001), Phase Tensor (Bibby et al., 2005) and WALDIM (Marti et al., 2009). Bahr criteria may fail in some specific dimensionality cases and can't be applied in such cases (Ledo et al., 2002; Martı et al., 2005). Extended Groom Bailey Decomposition follows an assumption for the type of dimensionality (2D or $3 D / 2 D$ ), and examines how well the data fit this assumed model, and extracts the best fitting regional $1 \mathrm{D}$ or $2 \mathrm{D}$ impedances in presence of $3 D$ galvanic distortion. If the regional structure is $2 \mathrm{D}$, it can give best results, but it fails in 3D situations. The Phase Tensor, unaffected by galvanic distortion, provide a practical tool to easily obtain information about the dimensionality. It may also recover distorted regional impedances mostly in 1D, 2D and also in some 3D cases based on explicit assumption of dimensionality derived from phase tensor (Bibby et al., 2005). WALDIM (Marti et al., 2009) can give us a overview of inherent dimensionality and distortion parameters and estimate the approximate regional strike in situations such as $2 \mathrm{D}$ and $2 \mathrm{D}$ affected with small scale
3D conducting heterogeneity. In this study, we discussed the dimensionality results for Paraná basin for these various approaches and try to conclude which can give us a best regional strike approximation for MT data in a basin to invert it using best suited inversion routine.

\section{Methodology}

Swift Skew: Skew of impedance matrix or Swift's skew (Swift, 1967) indicates the dimensionality of the subsurface structure. This is independent of rotation of the tensor matrix and the values ranges generally from 0-0.5 (Vozoff, 1972). The values are less than 0.2 for 1-D and 2-D structures (Swift, 1967). Higher skew values indicate the more complex structure of the site. In some cases apparent resistivity and phase may be well behaved but skew will show high value if $3-D$ inhomogeneity is present (Berdichevsky et al., 1999). Skew measures impedance components differences to find out the deviation from 2-D structures (Swift, 1967). The diagonal terms are influenced strongly by noise.

Bahr Skew: Bahr skew (BS) is a measure of the local 3-D distortion of regional 2-D fields based on impedance phase, rather than on impedance magnitudes that is the conventional definition of skew (Vozoff, 1972). For BS greater than 0.3 , the data should be considered 3-D (Bahr, 1991).

Extended Groom Bailey Decomposition: Extended Groom Bailey decomposition method (McNeice and Jones, 2001) has been used to find the most consistent 2-D parameters from Paraná sites over different frequency band. Their approach includes using an analytical approximate Hessian as a starting solution to increase speed and stability. Both synthetic and real examples demonstrated the superiority of objective multisite, multifrequency analysis over a more subjective approach based on individual sites and frequency distortion models. Extended GB decomposition (McNeice and Jones, 2001) utilizes all the physical constraints implicit to the Groom Bailey decomposition model (Groom and Bailey, 1989) which imposed simultaneously on the all data set and a global minimum misfit solution achieved to estimate a regional Geo-electrical strike in presence of galvanic 3-D distortions.

Phase Tensor Analysis: The invariant parameters lambda and beta determine the dimensionality of regional impedance tensor (Caldwell et al., 2004; Bibby et al., 2005). Bibby et al. (2005) distinguished 1-D, 2-D and 3-D structures on the values of lambda and beta. In presence of 1-D structure lambda as well as beta are zero, for 2-D structure lambda is non-zero, while beta is zero and for 
GEOELECTRIC DIMENSIONALITY OF PARANÁ BASIN

3-D structure beta as well as lambda are non-zero. The criteria provided by the phase tensor parameters are necessary but not sufficient for determining the dimensionality of the regional conductivity structure (Bibby et al., 2005). The Dimensionality evaluated using phase tensor must give best results by considering the MT sites from different locations collectively. It has become common practice to combine the problem of determining the strike direction with distortion removal. The phase tensor separates the problems, providing the maximum information on the implicit dimensionality of the impedance tensor and, when appropriate, an explicit solution for the strike direction.

WALDIM: WALDIM (Marti et al., 2009), a FORTRAN code, was used to perform the dimensionality analysis of Paraná MT sites. This code was based on Weaver et al. (2000) criteria. The code computes the type of dimensionality corresponding to each sites and frequency, and computes related parameters, such as strike direction and distortion parameters, with their errors. Weaver et al. (2000) presented a dimensionality study based on sets of rotationally invariant scalars computed from the observed MT impedance tensor. The set of eight invariants (known as WAL invariants), seven independent $\left(\mathrm{I}_{1}, \mathrm{I} 2, \mathrm{I} 3, \mathrm{I}, \mathrm{I}\right.$, $16,17)$ and a dependent one $(Q)$, was defined in a way that the invariants can be represented in a Mohr circle diagram, with the exception of two ( $I_{1}$ and $\left.I_{2}\right)$ they are non-dimensional and normalized to unity, and their vanishing has a physical interpretation, specifically related to the geoelectric dimensionality. Based on these WAL invariants, Marti et al. (2009) developed a code for dimensionality analysis known as WALDIM. This provides a robust description of the dimensionality, and the parameters necessary for data correction prior to modeling.

\section{Geological Framework}

The Paraná basin in southern Brazil is an intracratonic basin located on the stable South American continental platform. The cratons that surround it are the São Francisco craton to the north, the Guaporé block northwest, southward continuation of the Amazon craton. Limits to Paraná basin is Quaternary basins to the west, Pantanal to the north, and the Chaco-Paraná to the south (Figure 1). The basin was formed in alternating marine and continental environment during Paleozoic period, forming the pre-volcanic sequences (Gama et al., 1982; Melfi et al., 1987). In the Early Cretaceous, intense volcanic activity formed the Serra Geral Formation, mainly composed of tholeiitic basalts and rare rhyodacytes and rhyolites (<3\%; Piccirillo et al., 1987). Paraná basin is classified as a Large Igneous Province (LIP) due to its large dimension(Bryan and Ernst, 2008). In the Late Cretaceous, northern part of the basin subsided and the post-volcanic rocks of the Bauru Group were deposited. MT soundings locations for all three profiles P1, P2 and P3 lying in the southern portion of Paraná basin are shown in Figure 1. The parallel profiles $\mathrm{P} 1$ and $\mathrm{P} 2$ are taken with an azimuth of orientation $\sim \mathrm{N} 42 \mathrm{~W}$, whereas profile $\mathrm{P} 3$ is orthogonal to profiles $\mathrm{P} 1$ and $\mathrm{P} 2$. Profiles $\mathrm{P} 1$ and P2 covers post-volcanic Bauru group of rocks , cenozoic sediments and Serra Geral formations laterally. whereas, Profile P3 covers mainly Bauru and Serra Geral formations.

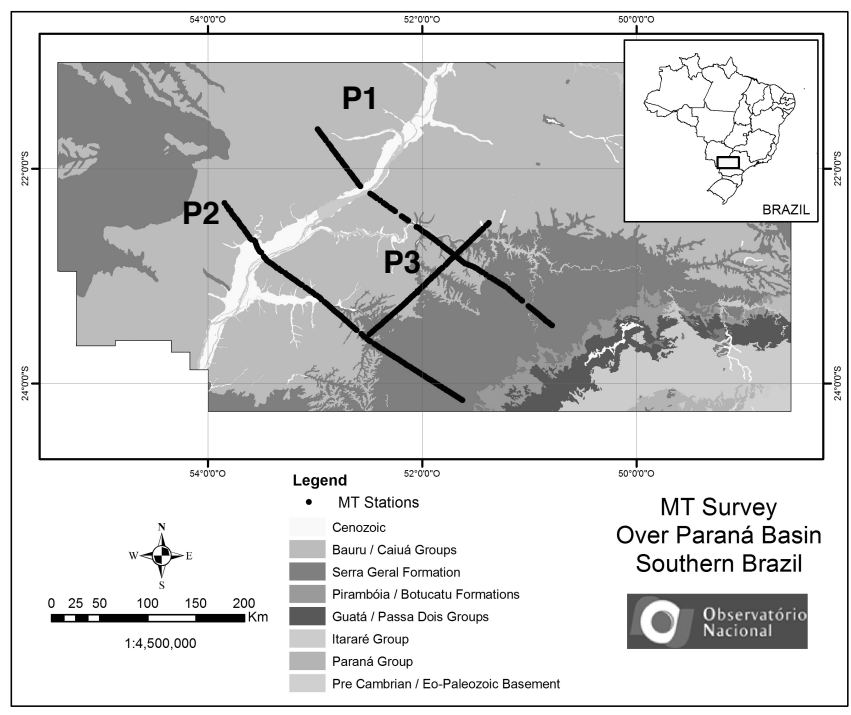

Figure 1. Geological Map of Paraná Basin along with all 3 MT profiles $P 1, P 2$ and $P 3$.

\section{Results and Discussion}

Dimensionality over Paraná Basin (Fig. 2)

Swift skew is almost zero for most of the frequencies along all three regional MT profiles. Swift skew is unable to identify the 3D behavior mostly for frequencies less than $0.1 \mathrm{~Hz}$ except some places. Bahr skew values are very small less than 0.3 mostly for frequencies up to 0.1 $\mathrm{Hz}$ whereas, it becomes more than 0.3 abruptly for frequencies smaller than $0.1 \mathrm{~Hz}$. The dimensionality information derived from Bahr skew is almost similar like phase tensor dimensionality parameter lambda and beta. As we discussed in the theory of phase tensor analysis the values of beta is mostly very small lying in between $\pm 1^{\circ}$ for higher and intermediate frequency ranges up to $0.1 \mathrm{~Hz}$ for all three profiles $\mathrm{P} 1, \mathrm{P} 2$ and $\mathrm{P} 3$ respectively. This behavior of beta values indicates towards 1-D and 2$D$ structures. In case of very low frequencies, the beta values are becoming non-zero lying close to $\pm 5^{\circ}$, indicating the presence of 3-D structures corresponding to these frequencies for all the three profiles. In obtained lambda map, the lambda values are very small for higher and intermediate frequencies up to $0.1 \mathrm{~Hz}$ lying in between $0-0.1$. The small lambda values together with small beta values for high and intermediate frequencies confirms the presence of 1-D features at shallow and intermediate depths. In case of smaller frequencies less than $0.1 \mathrm{~Hz}$ the lambda values are more than 0.1 along with non-zero values of beta at the same frequencies, shows a departure from 2-D behavior, and indicating the presence of 3-D features for these frequencies. The WALDIM results are mostly showing $1 \mathrm{D}$ and $2 \mathrm{D}$ bodies for frequencies greater than $0.1 \mathrm{~Hz}$ and mostly 3D bodies for frequencies less than $0.1 \mathrm{~Hz}$ for all $3 \mathrm{MT}$ profiles. WALDIM also confirms that MT data is of affected by 3D galvanic distortion at intermediate and longer periods. 

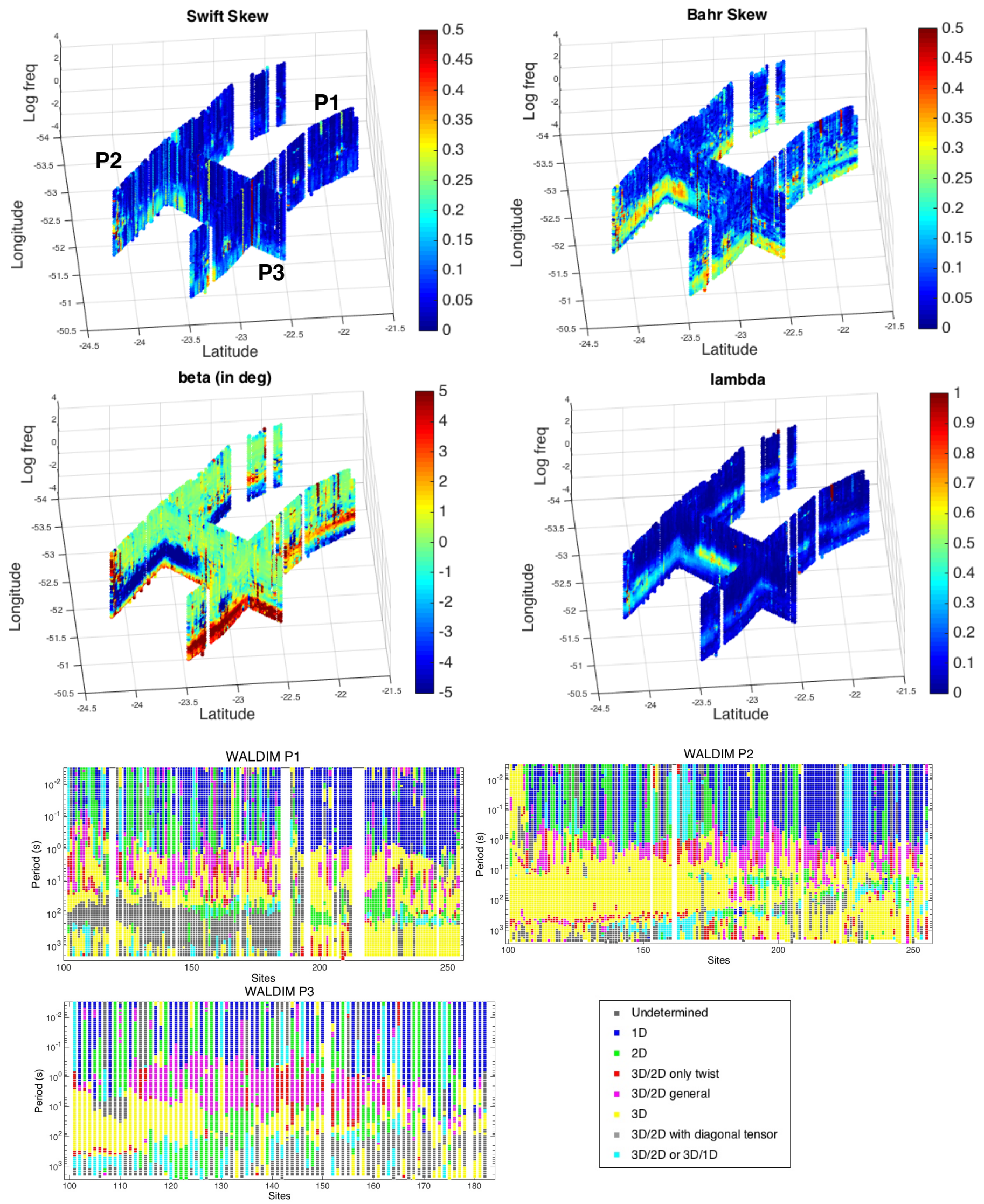

Figure 2. Dimensionality parameters i) Swift skew ii) Bahr skew iii) Beta from phase tensor iv) lambda from phase tensor v) WALDIM for all 3 Paraná MT profiles. 
Directionality over Paraná Basin (Fig. 3)

Groom Bailey strike depicts a regional strike of N55W for frequency range in between $0.1 \mathrm{~Hz}-0.001 \mathrm{~Hz}$ for all the three MT profiles. For profile P3 two strike directions among them, one is similar like P1 and P2, i.e., N55W, whereas other one is E-W. Phase tensor strike, alphabeta, obtained from phase tensor analysis is consistent with dimensionality results as there is no strike trend visible in phase tensor strike map for frequencies up to $0.1 \mathrm{~Hz}$ as it belongs to 1-D situation. For frequencies, less than $0.1 \mathrm{~Hz}$ there is a strong regional trend for the Geo-electrical strike, N55W, which insists it to be almost parallel to the profile orientation. This trend is also varying its direction from $0^{\circ}$ to $-30^{\circ}$ from the profile orientation suggesting towards the strong 3-D possibilities. The results from phase sensitive strike is almost same as phase tensor strike. Tipper strike for Paraná basin depicts similar results likewise phase tensor and phase sensitive strikes but the direction of regional current flow, is modified for 3D case for frequencies less than $0.1 \mathrm{~Hz}$. The regional current flow direction for $3 \mathrm{D}$ situation is varying from $+50^{\circ}-50^{\circ}$. As tipper strike is mostly sensitive to lithological variation, the large regional variation of it also confirms the presence of 3-D bodies for lower frequencies or greater depths.
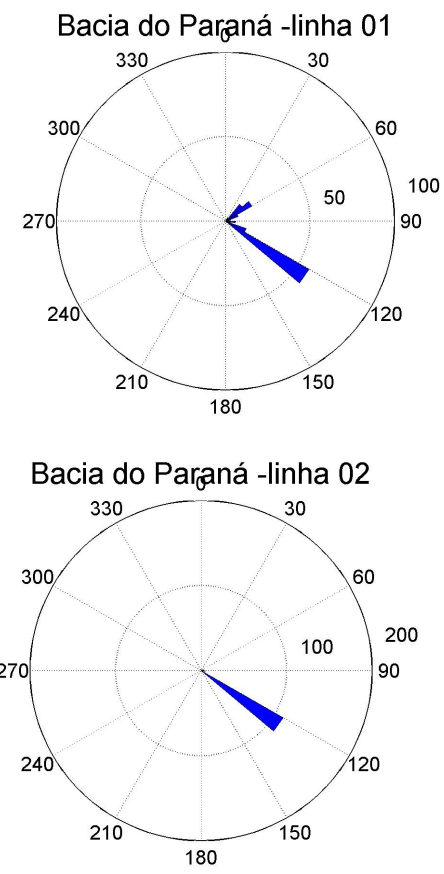

Bacia do Paraná -linha 03

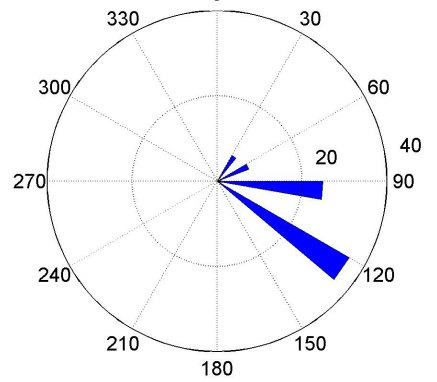

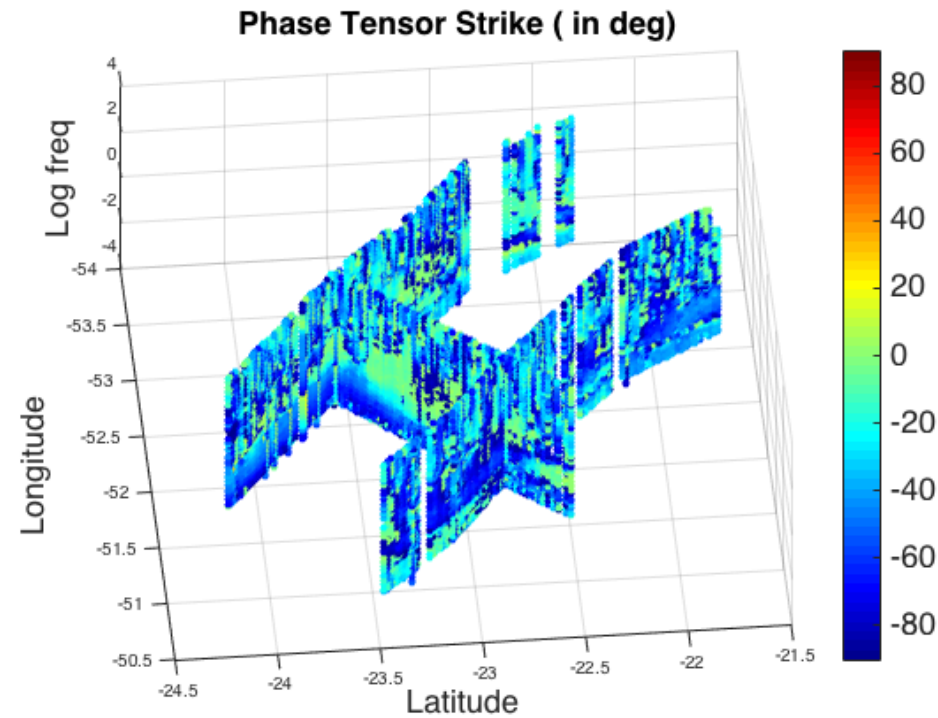
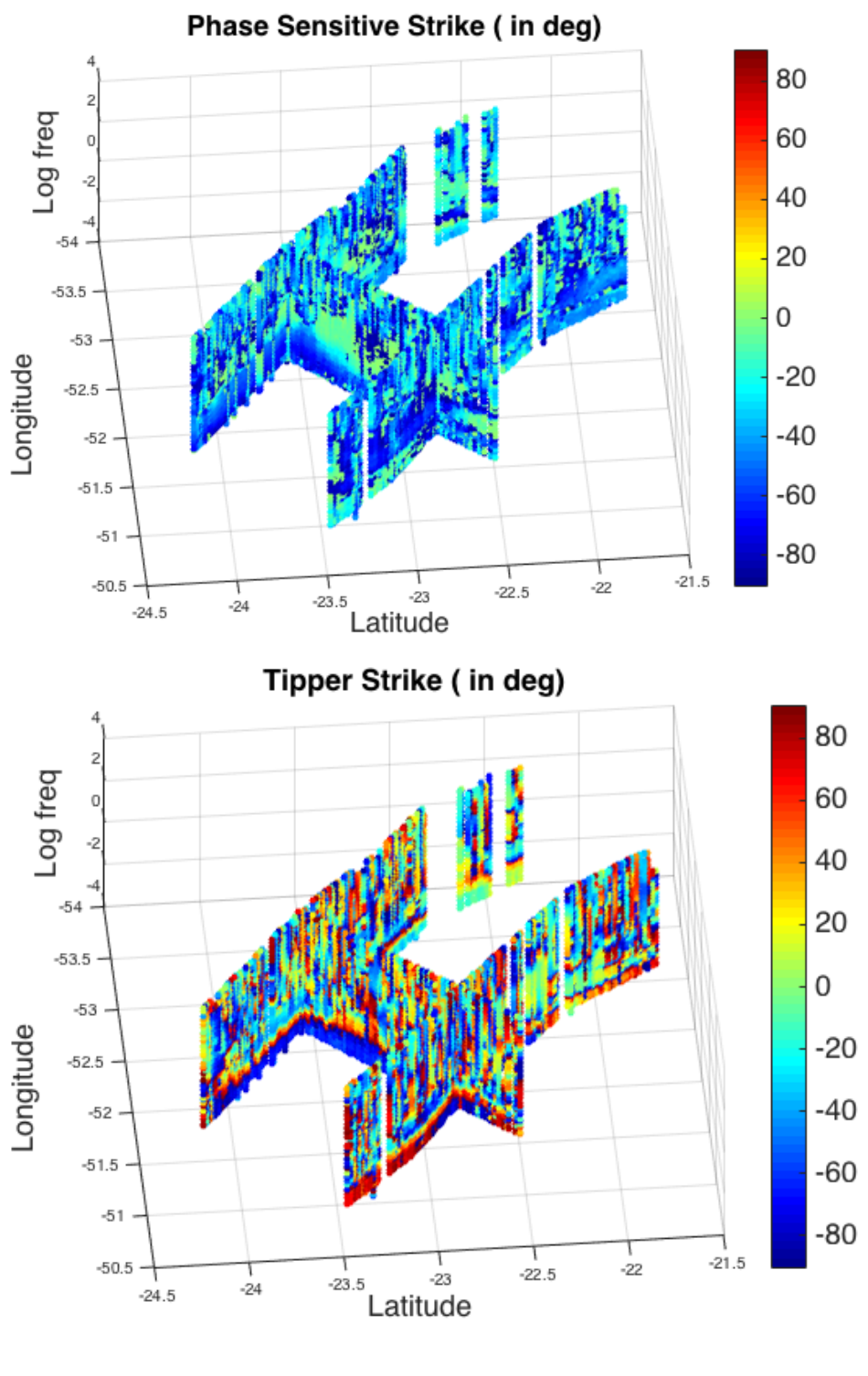

Figure 3. Directionality by i) Groom Bailey strike, ii) Phase sensitive strike, iii) Phase tensor strike, and iv) Tipper strike for all 3 Paraná MT profiles for frequencies in between $320 \mathrm{~Hz}-0.0014 \mathrm{~Hz}$. 


\section{Conclusions}

The dimensionality analysis from Phase tensor and WALDIM are almost consistent. Extended Groom Bailey decomposition works well for $2 \mathrm{D}$ periods in presence of small scale 3D galvanic distortion. The dimensionality for Paraná Basin infer 1D features for frequencies up to 0.1 $\mathrm{Hz}$ and strong 3D indication for frequencies less than 0.1 $\mathrm{Hz}$. For 2D MT periods along all 3 profiles the Geoelectrical strike is $\sim \mathrm{N} 55 \mathrm{~W}$, consistent with regional geological trend. The results from WALDIM and Extended Groom Bailey decomposition depicts the presence of small scale 3D conducting heterogeneities, inducing the galvanic distortion at most of the longer periods.

\section{Acknowledgements}

We thank ANP for supporting this project. VPM is thankful to $\mathrm{ON}$ for providing support to present this work in SBGf.

\section{References}

Bahr, K., 1991. Geological noise in magnetotelluric data: a classification of distortion types. Physics of the Earth and Planetary Interiors 66: 24-38.

Bibby, H.M., Caldwell, T. G., \& Brown, C. 2005. Determinable and non-determinable parameters of galvanic distortion in magnetotellurics. Geophys. J. Int., 163: 915-930.

Berdichevsky, M. N. 1999. Marginal notes on magnetotellurics. Surv. Geophys., 20: 341-375.

Bryan, S.E., \& Ernst, R.E., 2008. Revised definition of Large Igneous Province (LIPs). Earth Science Reviews, 86: $175-202$.

Caldwell, T.G., Bibby, H.M., \& Brown, C., 2004. The magnetotelluric phase tensor. Geophysical Journal International 158: 457-469.

Gama, E.J., Bandeira, A.N.J., \& França, A.B., 1982. Distribuição especial e temporal das unidades litoestratigráficas paleozoicas na parte central da bacias do Paraná. Revista Brasileira de Geociências, 12 (4): 579-590.

Groom, R.W., \& Bailey, R.C., 1989. Decomposition of the magnetotelluric impedance tensor in the presence of local three-dimensional galvanic distortion. Journal of Geophysical Research, 94:1913-1925.

Ledo, J., Queralt, P., Marti', A., \& Jones, A.G., 2002. Twodimensional interpretation of three-dimensional magnetotelluric data: an example of limitations and resolution. Geophysical Journal International, 150:127139.

Marti, A., Queralt, P., Jones, A.G., \& Ledo, J., 2005. Improving Bahr's invariant parameters using the WAL approach. Geophysical Journal International, 163: 38-41.

Marti' A., Queralt, P., \& Ledo, J. 2009. WALDIM: A code for the dimensionality analysis of magnetotelluric data using the rotational invariants of the magnetotelluric tensor. Computers \& Geosciences, 35: 2295-2303.

McNeice, G., \& Jones, A.G., 2001. Multisite, multifrequency tensor decomposition of magnetotelluric data. Geophysics, 66: 158-173.

Melfi, A.J., Piccirillo, E.M., \& Nardy, A.J.R., 1987. Geological and magmatic aspects of the Paraná basin an introduction. In: Piccirillo, E.M., Melfi, A.J. (Eds.), The Mesozoic Flood Volcanism of the Paraná Basin: Petrogenetic and Geophysical Aspects. Universidade de São Paulo, Instituto Astronômico e Geofísico, 1-13.

Piccirillo et al. (09 co-authors)1987. Petrochemistry of continental flood basalterhyolite suites and relate intrusive from the Paraná basin (Brazil). In: Piccirillo, E.M., Melfi, A.J. (Ed.), The Mesozoic Flood Volcanism of the Paraná Basin: Petrogenetic and Geophysical Aspects. Universidade de São Paulo, Instituto Astronômico e Geofísico, 1-13.

Swift, C. M. 1967. A magnetotelluric investigation of an electrical conductivity anomaly in the South Western United States. Ph.D. Thesis, M.I.T., Cambridge, Mass.

Vozoff, K. 1972. The magnetotelluric method in the exploration of sedimentary basins. Geophysics 37: 98141.

Weaver, J.T., Agarwal, A.K., \& Lilley, F.E.M., 2000. Characterization of the magnetotelluric tensor in terms of its invariants. Geophysical Journal International, 141:321336. 